This item was submitted to Loughborough's Research Repository by the author.

Items in Figshare are protected by copyright, with all rights reserved, unless otherwise indicated.

\title{
Reciprocal effects of motivation in physical education and self-reported physical activity
}

PLEASE CITE THE PUBLISHED VERSION

http://dx.doi.org/10.1016/j.psychsport.2017.01.003

PUBLISHER

(C) Elsevier

VERSION

AM (Accepted Manuscript)

\section{PUBLISHER STATEMENT}

This work is made available according to the conditions of the Creative Commons Attribution-NonCommercialNoDerivatives 4.0 International (CC BY-NC-ND 4.0) licence. Full details of this licence are available at: https://creativecommons.org/licenses/by-nc-nd/4.0/

\section{LICENCE}

CC BY-NC-ND 4.0

\section{REPOSITORY RECORD}

Taylor, lan. 2017. "Reciprocal Effects of Motivation in Physical Education and Self-reported Physical Activity". Loughborough University. https://hdl.handle.net/2134/24046. 
2 Running head: PE MOTIVATION AND PHYSICAL ACTIVITY

3

4

5

6

7

8

9 Reciprocal effects of motivation in physical education and self-reported physical activity

10

11

12

13

14 Manuscript submitted: July $29^{\text {th }}, 2016$

15 Manuscript resubmitted: October $27^{\text {th }}, 2016$

16 Manuscript second resubmission: January $13^{\text {th }}, 2017$

17 Manuscript third resubmission: January $16^{\text {th }}, 2017$

18

19

20

21 Author Note: This study was supported by a grant from the Nuffield Foundation

22 (SGS/39228) awarded to the author. The author would like to acknowledge Dr Chris Spray,

23 Dr Chris Lonsdale and Dr Natalie Pearson for their insightful comments and contributions

24 during the preliminary stages of this study.

25 
Abstract

27 Objectives: The present study tested whether self-reported school and leisure-time physical activity have a reciprocal relationship with Physical Education (PE)-based motivational regulations described by self-determination theory. Participants were 635 11- and 12-year-old school children from the United Kingdom.

31 Design \& Method: A cross-lagged longitudinal design over two time points was employed. Study hypotheses were analyzed using latent factor reciprocal effects models.

Results: Following temporal invariance tests, data revealed positive relationships between both types of physical activity and subsequent changes in autonomous motivation, but not the oft-stated reverse relationship. No relationships were observed involving introjected regulation. Theoretically aligned relationships between external regulation and changes in physical activity were observed, but no reverse relationships. Both types of physical activity behavior were negatively associated with changes in amotivation in PE, but surprisingly, amotivation in PE positively predicted changes in leisure-time physical activity.

Conclusions: In general, physical activity participation may help children internalize reasons

41 for partaking in PE and foster self-determination. However, the widespread theory that selfdetermined PE motives can develop school and leisure-time physical activity participation was not compellingly demonstrated.

Keywords: health promotion, time-lagged, self-determined motivation, controlling motivation 46 
51 Reciprocal effects of motivation in physical education and self-reported physical activity

\section{Introduction}

There is now strong evidence to suggest that general levels of physical activity in

children and adolescents are inadequate to accrue meaningful health benefits. Only $21 \%$ of boys and $16 \%$ of girls aged 5-15 years in the United Kingdom are meeting guidelines for recommended physical activity levels (Health and Social Care Information Centre, 2014).

Schools have been documented as important settings to combat these insufficient levels of activity (Centers for Disease Control \& Prevention, 2011). In particular, physical education (PE) classes may help develop healthy physical activity behavior in school and in leisuretime (Office for Standards in Education Children's Services \& Skills, 2013). There is, therefore, compelling reason to explore PE-related phenomena with a view to inform the promotion of children's physical activity in various contexts.

Self-determination theory (SDT; Deci \& Ryan, 2012) is a well-evidenced framework that focuses on human motivation and has been applied to the study of children's motivation in PE contexts (e.g., Ntoumanis, 2012). A key postulate of the theory distinguishes between types of motivation that vary in their levels of self-determination. Intrinsic motivation represents complete self-determination and refers to performing an activity for its own sake, because the activity is interesting and enjoyable (Deci \& Ryan, 2012). In a descending order of self-determination, four different types of extrinsic motivation are also defined within the theory: Integrated regulation (i.e., partaking in an activity because it represents the essence of the self. Note that this motive is generally not considered in child samples, possibly due to an underdeveloped sense of self; Vallerand, 2001), identified regulation (i.e., pursuit of an activity to attain personally meaningful outcomes), introjected regulation (i.e., engaging in a behavior to feel worthy or to avoid feelings of guilt or shame), and external regulation (i.e., engagement to obtain a reward or avoid punishment; Deci \& Ryan, 2012). An individual may 
76 also completely lack any reason to participate in an activity and is, therefore, amotivated

77 (Deci \& Ryan, 2000). Broadly speaking, autonomous motivation (i.e., intrinsic motivation and identified regulation) in PE has been positively associated with physical activity behavior, whereas controlling regulations (i.e., introjected regulation and external regulation) and amotivation have been unrelated or negatively related to physical activity in cross-sectional

81 (Aelterman et al., 2012), prospective (Standage, Gillison, Ntoumanis, \& Treasure, 2012), and longitudinal work using multilevel modeling (McDavid, Cox, \& McDonough, 2014; Taylor, regulation has, on occasion, been positively associated with physical activity (e.g., timeinvariant individual differences in sixth grade students; McDavid et al., 2014). In fact, this positive relationship has been observed in a meta-analysis of self-determined motivation and physical activity in children and adolescents (Owen, Smith, Lubans, Ng, \& Lonsdale, 2014). With the exception of one study that focused on physical activity in physical education classes (Aelterman et al., 2012), physical activity is usually operationalized within broad leisure-time contexts, and measured in a variety of ways (i.e., self-report, pedometer, and accelerometer).

This body of research stems from theory suggesting that autonomous motivation leads to favorable behavior. The hierarchical model of intrinsic and extrinsic motivation, for example, proposes that motivation in any given context leads to behavioral consequences in that context and other related settings (Vallerand, 2001). Therefore, there is an assumption that a temporal or causal sequence exists between motivation in $\mathrm{PE}$ and subsequent physical activity. However, most studies testing this process have employed a cross-sectional design (Owen et al., 2014). Equally plausible, therefore, is the reverse process whereby physically active individuals are more likely to become more autonomously motivated in PE classes. A similar argument was put forward, and subsequently tested, regarding psychological need 
101 satisfaction (a separate, but related, motivational concept associated with SDT) and physical activity (Gunnell, Bélanger, \& Brunet, 2015). All children have a natural inclination to internalize motives for behavior and this is only prevented under conditions that thwart

104 fundamental psychological needs (Deci \& Ryan, 2000). It is reasonable to assume, therefore, 105 that more time spent being active provides greater opportunity for the internalization of 106 associated activities, such as PE class participation, to occur (i.e., increased autonomous motivation, lower controlling motivation and amotivation).

This reciprocal process has been largely ignored in the literature but can be tested using longitudinal data in which motivation and physical activity are evaluated on at least two occasions. Reciprocal effects models have been used to consider alternative processes, such 111 as academic self-concept and achievement (e.g., Marsh, 1990) and motivational quality and burnout (Lonsdale \& Hodge, 2011). Statistically significant paths from initial motivation to subsequent physical activity and from initial physical activity to subsequent motivation

114 would indicate the existence of reciprocal effects. This type of autoregressive cross-lagged 115 analysis provides stronger evidence for relationships than cross-sectional results because it 116 accounts for cross-sectional associations between both constructs, as well as the temporal 117 stability of each construct (i.e., intra-individual change is measured). The reciprocal effects 118 hypothesis has significance for theorists who propose that self-determined motivation is a 119 crucial mechanism for physical activity promotion (e.g., Owen et al., 2014). Complementary 120 to this proposal is the potential for physical activity participation to create engaged and self121 determined students in PE classes.

122 A further focus in the present study is the testing of sequential relationships between 123 PE motivation and different periods of physical activity, namely school and leisure-time.

124 Self-determination in PE class has been associated with higher levels of objectively measured 125 (via step counts) physical activity in the PE class (Lonsdale, Sabiston, Raedeke, Ha, \& Sum, 
126 2009). Theories that have stemmed from SDT, such as the hierarchical model of motivation

127 (Vallerand, 2001) and the trans-contextual model of autonomous motivation (Hagger \&

128 Chatzisarantis, 2015) also describe how motivation in one context can influence behavior in

129 another. As such, motivation in PE has been positively associated with self-reported physical

130 activity in leisure-time contexts (e.g., Barkoukis, Hagger, Lambropoulos, \& Torbatzoudis,

131 2010; Hagger et al., 2009; Taylor et al., 2010). It is currently unknown whether motivation in

132 PE is correlated with a more general consideration of school physical activity which includes

133 recess or lunch-time. In the present study, therefore, leisure-time physical activity (after

134 school hours, evenings, and weekends) and school-based physical activity (PE class, recess,

135 and lunch time) were distinguished. Also, the aforementioned models do not consider

136 whether behavior in one context can influence motivation in another. Evidence exists to

137 suggest that out of school sport participation is associated with stable amotivation in PE,

138 whereas, non-participation is associated with increasing amotivation (Ntoumanis, Barkoukis,

139 \& Thøgersen-Ntoumani, 2009). The influence of past behavior on subsequent cognition has

140 been acknowledged in some theoretical frameworks, such as the theory of planned behavior

141 (Hagger, Chatzisarantis, \& Biddle, 2001; Rhodes \& Courneya, 2003), but has received little

142 attention as an antecedent of self-determination.

143 To summarize, the present study aimed to test the reciprocal longitudinal associations

144 between individual motivational regulations towards PE and self-reported physical activity.

145 Integrating previous evidence (Aelterman et al., 2012; McDavid et al., 2014; Standage et al.,

146 2012; Taylor et al., 2010; 2014) with theorized internalization processes (Deci \& Ryan, 2000)

147 led to the hypothesis that motivation in PE and physical activity would have a mutually

148 dependent relationship. This challenges the unidirectional causal relationship from motivation

149 to behavior that is often assumed. Stronger evidence of this reciprocal relationship was

150 expected between PE motivation and school physical activity, rather than leisure-time 
151 physical activity, because of the proximity of context (PE and school versus PE and leisure-

152 time). Stronger evidence was also expected for the positive relationships involving intrinsic

153 and identified regulation, compared to non-significant or negative relationships involving

154 introjected regulation, external regulation and amotivation. This was hypothesized because

155 autonomous regulations tend to have a greater association with physical activity behavior,

156 compared to controlling regulations or amotivation (Owen et al., 2014).

\section{Method}

\section{Participants and Procedures}

Secondary school students participated in the study $(N=635$, including 466 11-yearolds, 150 12-year-olds, 19 unspecified, 58\% male) who were sampled from 65 classes in nine secondary schools based in Wales and central England. Eighty-eight percent of participants reported their ethnicity as White, one percent as Black, four percent as South Asian, and six percent as Other. None of the sampled participants were included in a separate study that took place within the same broader project (i.e., Taylor et al., 2014). Fifteen participants did not report the class that they belonged to, so they could not be included in the analysis because the nested class structure was accounted for. One hundred sixty-nine participants did not complete measures during the second time point, either for logistical reasons or absence from school. However, all analyses conducted in this study used the full sample of 620 participants to avoid a suboptimal listwise deletion strategy (Newman, 2014). On average, participants reported a level of involvement in leisure-time activity that was slightly over the scale

171 midpoint $[M(S D)=3.25(0.87)$ at time 1 and 3.42(0.87) at time 2] and slightly under the scale 172 midpoint for school-based physical activity $[M(S D)=2.86(0.93)$ at time 1 and 2.83(0.90) at 173 time 2].

Following approval from a University Ethical Committee, consensual procedures

175 corresponding with the American Psychological Association regulations were followed with 
176 teachers, parents of prospective participants, and the students. At the beginning of a

177 scheduled PE lesson, students were asked to answer the study questionnaire honestly and

178 were told that there were no correct or wrong answers. Students were asked to complete all

179 measures in November or December 2011 (Time 1) and March or April 2012 (Time 2). A

180 range of activities were taught in the classes over the course of the study, including soccer,

181 athletics, hockey, and basketball.

182 Measures

183 PE Motivation. The different types of motivation were measured using the 20 items

184 (four for each subscale) developed by Goudas, Biddle, and Fox (1994), which followed the 185 stem, “I take part in PE. ...” Example items are "Because it is fun” (intrinsic motivation), 186 “Because I want to learn sport skills” (identified regulation), "Because I would feel bad if I 187 didn’t” (introjected regulation), “Because I’ll get in trouble if I don't” (external regulation), 188 and "But I think I'm wasting my time in PE" (amotivation). Students responded to all items 189 using a 7-point scale ranging from 1 (not at all true) to 7 (very true). Lonsdale and colleagues 190 (Lonsdale, Sabiston, Taylor, \& Ntoumanis, 2011) provided supportive evidence regarding the 191 factor structure and internal consistency of the measure.

192 Physical activity. We used six items from the Physical Activity Questionnaire for 193 Older Children (PAQ-C; Crocker, Bailey, Faulkner, Kowalski, \& McGrath, 1997) to measure 194 children's physical activity. The PAQ-C measures 7-day recall of general levels of moderate 195 and vigorous physical activity by utilizing memory cues, such as lunch time and evenings to 196 enhance recall. Three items were used to measure school physical activity (during PE, break 197 time and lunch) and three items for leisure-time physical activity (after school hours, in the evenings and weekends). An example item is, "In the last seven days, on how many evenings did you do sports, dance or play games in which you were very active?” All items from the original PAQ-C were not used because some did not allow for differentiation of school and 
201 leisure-time, which was a purpose of the study. Students then responded on a 5-point scale

202 with higher scores reflecting greater amounts of physical activity. Crocker et al. (1997)

203 demonstrated internal consistency and validity in similar aged samples, however, see the

204 Results section for evidence of factorial validity when using school and leisure-time items as

205 indicators of distinct types of physical activity.

206 Data Analysis

207

All analyses were conducted using Mplus software (Version 7.11; Muthén \& Muthén, 1998 - 2012). Maximum likelihood estimation with robust standard errors (i.e., MLR estimator in Mplus) and the TYPE = COMPLEX command were used to account for potential clustering effects associated with pupils being nested within different classes (Hox, 2010). Each questionnaire item was used as an indicator of its respective latent factor and missing data was handled using the full information maximum likelihood method (Newman, 2014). The primary indices used for estimating goodness of fit of the models were the Root Mean Square Error of Approximation (RMSEA < .08), Comparative Fit Index (CFI) and Tucker-Lewis Index (TLI \& CFI > .90, however, values closer to .95 have also been endorsed; Hu \& Bentler, 1999).

Prior to the main analysis, preliminary confirmatory factor analysis was carried out to test the factorial structure of the study measures. In particular, previous research has demonstrated consistently high inter-factor correlations between intrinsic motivation and

220 identified regulation (Lonsdale et al., 2011); therefore, this possibility was explored by

221 examining the latent factors correlations between these constructs. The correlations between 222 the two physical activity forms were also inspected to confirm whether the two types were 223 distinguishable.

Next, measurement invariance across time points was tested in line with previous 225 work (Marsh et al., 2010; Marsh, Nagengast, \& Morin, 2013). This involved constructing a 
226 baseline configural measurement model (Model 1) in which parameters were allowed to

227 differ across time points, all loadings were freely estimated and factor variances were fixed to

2281 (Byrne, 2012). In accordance with guidelines on constructing reciprocal effects models,

229 covariance terms among factors measured at the same time point were freely estimated and

230 the uniqueness term associated with each indicator score at time 1 was allowed to correlate

231 with the same term at time 2 (Marsh, Byrne, \& Yeung, 1999).

232 Increasingly constrained models were then tested. Chi-square difference tests when

233 employing robust maximum likelihood estimation can be overly severe (Brown, 2006),

234 therefore, the main criterion for accepting the constrained model over the previous less

235 constrained model (i.e., invariance) was $\Delta$ CFI $\leqslant .01$ (Chen, 2007; Cheung \& Rensvold,

236 2002). Additionally, $\triangle$ RMSEA $\leqslant .015$ was also considered indicative of invariance (Chen,

237 2007). Model 2 tested weak invariance with factor loadings constrained to be equal over time

238 and the factor variances at the second time point freely estimated. Model 3 tested strong

239 invariance by additionally constraining item intercepts and freely estimating the factor means

240 of the second time point. Model 4 tested a strict invariance model with factor loadings,

241 intercepts, and uniqueness terms constrained to be equal over time. Two further models

242 testing less commonly evaluated aspects of invariance were constructed (see Marsh et al.,

243 2013). Specifically, factor variances and covariances were additionally constrained in Model

2445 , followed by factor means in Model 6.

245 Our primary analysis involved structural equation modeling to test the reciprocal

246 effects model (shown in Figure 1), which involved the simultaneous modeling of all

247 relationships involving time 1 motivation - time 2 physical activity and time 1 physical

248 activity - time 2 motivation. The estimation method and fit criteria were the same as the

249 preceding invariance analyses. 
251

252

253

254

255

256

257

258

259

260

261

262

263

264

265

266

267

268

269

270

271

272

273

274

275

\section{Preliminary Analyses}

As expected, the inter-factor correlation between intrinsic motivation and identified regulation was high (.98 at time 1 and .99 at time 2). As a result, the two regulations were merged with all eight items loading onto a single ‘autonomous motivation’ factor. This strategy has been used in previous research (e.g., Standage, Duda, \& Ntoumanis, 2003). The inter-factor correlations between the two types of physical activity were .44 (at time 1) and .56 (at time 2) suggesting the existence of two related, yet discernible types of physical activity.

Factor loadings in the baseline configural measurement model (Model 1) ranged from .35 to .86 . Composite reliability scores and latent factor correlations for all variables are presented in Table 1. All composite reliability values were satisfactory. Latent factor correlations indicated that the motivational regulations largely conformed with the hypothesized simplex structure proposed by SDT researchers (e.g., Ryan \& Connell, 1989). In general, positive correlations were observed between autonomous motivation, introjected regulation and the two forms of physical activity. External regulation was weakly and negatively associated with leisure-time physical activity at time 1 and 2. A small negative correlation was observed between external regulation and school physical activity at time 2 . Amotivation was moderately and negatively correlated with both types of physical activity at both time points. School and leisure-time physical activity were moderately and positively correlated with each other.

\section{Measurement Invariance}

The fit indices for the models testing invariance can be seen in Table 2. $\Delta$ CFI and $\triangle$ RMSEA did not meaningfully deteriorate following the addition of constraints, signifying invariance in each step. In other words, the latent factors in the present study are measured identically across time points and full measurement invariance is supported (Marsh et al., 
276 2010; Marsh et al., 2013). As such, the reciprocal effects model was based on full invariance,

277 with the exception that the covariances were freely estimated across time points because

278 time-specific covariances in autoregressive cross lagged models do not have the same

279 meaning across time points.

280 Reciprocal Effects Model

281

The estimated reciprocal effects model (Model 7) demonstrated acceptable fit using

282 the same criteria used to assess models testing invariance (see Table 2). Standardized path coefficients are displayed in Table 3. Unsurprisingly, all time 1 measurements were positively and strongly associated with the time 2 measurements of the same construct.

Regarding the substantive associations, the motivational regulations in PE at time 1 did not predict time 2 school physical activity, apart from weak evidence found for the negative relationship between school physical activity and external regulation $(p=.07)$. Time 1 external regulation in PE negatively predicted time 2 leisure-time physical activity, whereas time 1 amotivation in PE positively predicted time 2 leisure-time physical activity. Both relationships were small-moderate in magnitude. Time 1 introjected regulation was not associated with time 2 leisure-time physical activity. physical activity positively predicted time 2 autonomous motivation in PE (both relationships were small in magnitude). Neither type of physical activity at time 1 predicted introjected or external regulation in PE at time 2. School physical activity at time 1 negatively predicted amotivation at time 2, and weak evidence was found for a negative relationship between time

2971 leisure-time physical activity and time 2 amotivation $(p=.06$; both relationships small in magnitude). Explained variance of the time 2 dependent variables were similar with $R^{2}$ statistics ranging from .29- .35. 
defined within SDT, and self-reported physical activity. By doing so, the bidirectional and temporal associations between motivation and physical activity were put under rigorous scrutiny. Some conclusions drawn from the data align well with existing theory, but others are counter to postulates of SDT and related models of motivation. psychometric conclusions can be drawn from the data. First, high latent correlations between children's responses to intrinsic motivation and identified regulation meant that it was not possible to distinguish between the two motivational regulations. This issue has been raised previously and represents a shortcoming of SDT research and broader motivation science, in general (Lonsdale et al., 2011; Wigfield \& Cambria, 2010). Intuitively, one can value and identify with an activity that is not inherently enjoyable or interesting, but this distinction may require considerable reflection or guidance during completion of a questionnaire.

314 Perhaps a greater distinction between situational (enjoyment) and personal (value) interest 315 may be fruitful (Hidi \& Renninger, 2006). Alternatively, children’s motives may be more 316 simplistic and they largely value what they enjoy or find interesting. Whatever the underlying reason, conceptual and psychometric efforts to solve this issue are required.

319 adds to the ongoing process of validity testing of this instrument. This has not been reported 320 elsewhere and demonstrates that the latent factors tapping into the motivational regulations 321 are measured identically across time, albeit a relatively short period of a few months. The 322 physical activity questionnaire also demonstrated longitudinal invariance but it was adapted 323 from its original form, so this is not commented on further. Establishing longitudinal measurement invariance is a fundamental step towards a focus on internalization processes 325 proposed within SDT because we can assume that children's scores at initial measurement 
represent the same construct as scores at subsequent measurement points (Vandenberg \&

327 Lance, 2000). It would be of further interest to investigate longitudinal measurement invariance across longer periods to establish the impact of cognitive development (Knight \& Zerr, 2010).

Most observed relationships between motivation and physical activity were small or small-moderate in magnitude; however, this was to be expected given that intra-individual change in study variables was controlled for. Surprisingly, no evidence was found to suggest that autonomous regulation was associated with increases in either type of physical activity. This was not expected considering previous longitudinal work (McDavid et al., 2014; Taylor et al., 2010; 2014). The most obvious explanation is the different type of analysis used in the present study. The reciprocal effects models used here represent considerable rigor by controlling for measurement error, cross-sectional associations and temporal stability of each construct. The second, perhaps less obvious explanation given the weight of evidence to the contrary, is that motivation in PE does not influence school or leisure-time physical activity.

340 Although a primary objective of PE is to encourage life-long physical activity, there are

341 considerable contextual differences between PE and many contexts in which physical activity 342 takes place, such as the mandatory nature of PE and the organized curriculum focused on 343 teaching and learning. These differences make any strong trans-contextual associations less

344 likely, for instance, it is not unreasonable to imagine an adolescent despising PE class, but 345 enthusiastically engage in softball at weekends. In addition, PE classes are one of many 346 influences on physical activity behavior. It is possible that any one focus of intervention (e.g., 347 motivation in PE class) may have limited success in isolation but a multi-component 348 intervention targeting several influences may be successful (e.g., school and family; van 349 Sluijs, McMinn, \& Griffin, 2007). 
The lack of relationship between autonomous regulation and changes in physical

351 activity becomes more thought-provoking when considering that reverse effects were found

352 in the present study. Participants who reported high levels of school and leisure-time physical

353 activity reported increases in autonomous regulation in PE. This relationship is significant

354 because a dominant assumption within SDT-based research and associated theoretical

355 frameworks, such as Vallerand's (2001) hierarchical model, is that motivation leads to 356 subsequent behavioral consequences. This evidence questions that assumption and the largely

357 cross-sectional research that it is based on (Owen et al., 2014). Researchers using this

358 framework in applied and field studies should begin to consider the reverse process. This is

359 the first empirical demonstration that participating in physical activity may allow children to 360 internalize motives for similar activities, such as PE class engagement. This hypothesis is 361 further substantiated with the lack of evidence found in the present study to suggest that 362 physical activity facilitates low self-determined motives (i.e., introjected or external 363 regulation). Moreover, students with higher school physical activity subsequently reported 364 greater decreases in amotivation. There was also a trend to suggest that high leisure-time 365 physical activity similarly led to decreases in amotivation in PE. Put simply, engaging in 366 physical activity may allow children to find reason for engaging in PE class and foster self367 determined motives, such as enjoyment, interest and value. Without such engagement, these 368 opportunities would be missed. In contrast to autonomous motivation, there was no relationship between introjected

370 regulation in PE and changes in school or leisure-time physical activity. Some positive 371 relationships between introjected regulation and broad physical activity behavior have been 372 noted previously, however, these are usually observed when considering individual 373 differences (e.g., McDavid et al., 2014; see Owen et al., 2014 for a review). Longitudinal 374 examination of intra-individual change has typically unearthed non-significant relationships 
375 between introjected regulation in PE and physical activity (McDavid et al., 2014; Taylor et al., 376 2010). Given that controlling for initial levels or measuring within-person changes provides

377 stronger evidence for motivational processes, compared to cross-sectional analysis of

378 individual differences, we can begin to conclude that the desire to avoid guilt or maintain

379 self-worth in PE does not drive changes in physical activity behavior. The negative affective 380 experiences associated with introjected regulation, such as heightened anxiety, are likely to 381 attenuate any energizing properties of the motivation itself (Edmunds, Ntoumanis, \& Duda, 2006; Thøgersen-Ntoumani \& Ntoumanis, 2006; Gillison, Standage \& Skevington, 2011). In accordance with tenets of SDT, the results indicate that external regulation has a

384 detrimental impact upon children's physical activity levels in school or leisure-time. Null 385 relationships among external regulations and physical activity have been observed previously 386 in longitudinal designs (e.g., Taylor et al., 2010; 2014), but this study provides extra detail by examining the school and leisure-time distinction and controlling for initial levels of physical activity. Children’s motivation is, to some degree, an inherently natural intrapersonal phenomenon; however, the teacher can also play an important role (i.e., the organismic dialectical approach fundamental to SDT; Deci \& Ryan, 2000). Use of coercion and threat has been reported by PE teachers for many reasons (e.g., teaching norms, administrative pressure; Taylor, Ntoumanis, \& Smith, 2009). A dual approach to minimizing external regulation could be to curtail these strategies from teachers but also to develop values in

394 children that help reduce their orientation towards external, avoidance-based motives. No evidence was found linking amotivation in PE to changes in school physical activity. Unexpectedly, however, amotivation in PE was positively associated with increases 397 in leisure-time physical activity. Although rare, this theoretically abnormal finding has occurred previously (Taylor et al., 2014). The use of multilevel modeling to distinguish 
400 lead to the same conclusion, hence, this observation requires closer inspection in future work.

401 For example, on average the sample used in the present study reported low levels of

402 amotivation in PE. A broader sample representing the full range of amotivation would be

403 hard to obtain but would shed light on trans-contextual consequences of amotivation in PE.

404 The underlying reasons behind amotivation may also regulate this relationship (Ntoumanis,

405 Pensgaard, Martin, \& Pipe, 2004; Taylor et al., 2014). Interpersonal reasons for an absence of 406 motivation in PE (e.g., dislike of classmates) may lower activity in class but may not transfer

407 to leisure-time because the social milieu differs. In contrast, intrapersonal foundations for a

408 lack of motivation (e.g., "I don't like sweating in PE”) may facilitate trans-contextual

409 influence (e.g., "I don't like sweating at weekends either”). Although the mechanisms

410 describing the transfer of motivation from PE to leisure-time have been described in detail by

411 Hagger and colleagues’ conceptual framework (Hagger \& Chatzisarantis, 2015; Hagger,

412 Chatzisarantis, Barkoukis, Wang, \& Baranowski, 2005; Hagger, Chatzisarantis, Culverhouse,

413 \& Biddle, 2003; Hagger et al., 2009), the transfer of amotivation has not. It is likely that the

414 processes undergirding cross-contextual transfer of motivation will differ from those of an

415 absence of motivation. This work could be guided by previous attempts to sub-categorize

416 types of amotivation (Legault, Green-Demers, \& Pelletier, 2006) or the inter- versus intra-

417 personal foundations described above.

\section{Limitations and Future Directions}

These results provide insight into mutual relationships between PE experiences and

420 physical activity behavior; however, there are also limitations to address and further

421 questions to investigate. Physical activity was measured used self-report to obtain a relatively

422 large sample of students over two-time points. The self-report measure has been advocated

423 previously (Biddle, Gorely, Pearson, \& Bull, 2011); however, replication of the proposed

424 relationships using accelerometry would be useful to obtain more precise estimates of activity 
425 and remove potential effects of recall and response bias (Prince et al., 2008). Associations

426 between motivation and accelerometer-derived physical activity may be lower (compared to

427 self-reported physical activity) because acclerometers capture incidental activity as well as

428 purposeful 'motivated’ activity. Encouragingly, however, autonomous motivation has been

429 positively correlated with accelerometer-based moderate and vigorous physical activity in a

430 youth football sample (Fenton, Duda, Quested, \& Barrett, 2014).

431 Our results underscored the importance of reverse effects, whereby physical activity

432 behavior may influence autonomous motivation and amotivation, potentially via the

433 internalization process. Certain contextual conditions have been suggested to facilitate or

434 forestall internalization (e.g., autonomy supportive versus controlling contexts; Pelletier,

435 Fortier, Vallerand, \& Brière, 2001). A three-year longitudinal study in Greek PE

436 demonstrated perceptions of competence buffered against decreases in identified regulation

437 and increases in external regulation (Ntoumanis et al., 2009), which may provide clues into

438 contextual factors that facilitate internalization (e.g., competence enhancing feedback). It

439 would be fruitful to replicate this approach and ask whether specific conditions in physical

440 activity contexts are associated with increases in autonomous motivation over time, and

441 whether any observed changes influence subsequent physical activity behavior. Any such

442 longitudinal work may wish to consider greater number of time points than the present study

443 to enable a more nuanced analysis of temporal change using multilevel growth modeling

444 techniques (see Singer \& Willett, 2003). Longitudinal work capturing critical periods of

445 adolescent development, including school transitions and periods of accelerated biological

446 growth would also be beneficial (see Taylor et al., 2014; Sherar, Cumming, Eisenmann,

447 Baxter-Jones, \& Malina, 2010).

448 To summarize, the present study describes several reciprocal effects exploring the

449 relationship between motivation in PE and school and leisure-time physical activity. The 
450 hypothesis that motivation in PE and physical activity would have a mutually dependent

451 relationship was evidenced to some degree but not to the extent expected. Relationships were

452 not stronger when considering school physical activity, relative to leisure-time physical

453 activity. Overall, engagement in physical activity may help children internalize PE

454 engagement and foster-self-determination, but the prevailing assumption that self-determined

455 motivation can enhance school and leisure-time physical activity was not convincingly

456 observed.

457

458

459

460

461

462

463

464

465

466

467

468

469

470

471

472

473

474 


\section{References}

476 Aelterman, N., Vansteenkiste, M., Van Keer, H., Van den Berghe, L., De Meyer, J., \&

477

478

479

480

481

482

483

484

485

486

487

488

489

490

491

492

493

494

495

496

497
Haerens, L. (2012). Students’ objectively measured physical activity levels and engagement as a function of between-class and between-student differences in motivation towards physical education. Journal of Sport and Exercise Psychology, 34, 457-480.

Barkoukis, V., Hagger, M. S., Lambropoulos, G., \& Torbatzoudis, H. (2010). Extending the trans-contextual model in physical education and leisure-time contexts: Examining the role of basic psychological need satisfaction. British Journal of Educational Psychology, 80, 647-670.

Biddle, S. J. H., Gorely, T., Pearson, N., \& Bull, F. (2011). An assessment of self-reported physical activity instruments in young people for population surveillance: Project ALPHA. International Journal of Behavioral Nutrition and Physical Activity, 8, 1-9. doi: 10.1186/1479-5868-8-1

Brown, T. A. (2006). Confirmatory factor analysis for applied research. New York, NY: Guilford Press.

Byrne, B. (2012). Structural Equation Modeling with Mplus: Basic Concepts, Applications, and Programming. NY: Routledge

Centers for Disease Control and Prevention. (2011). School Health Guidelines to Promote Healthy Eating and Physical Activity. Morbidity \& Mortality Weekly Report, 60

Chen, F. F. (2007). Sensitivity of goodness of fit indices to lack of measurement invariance. Structural Equation Modeling, 14, 464-504.

http://dx.doi.org/10.1080/10705510701301834 
498 Cheung, G. W., \& Rensvold, R. B. (2002). Evaluating goodness-of-fit indexes for testing measurement invariance. Structural Equation Modeling, 9, 233-255.

500 http://dx.doi.org/10.1207/S15328007SEM0902_5

501 Crocker, P. R., Bailey, D. A., Faulkner, R. A., Kowalski, K. C., \& McGrath, R. (1997).

502 Measuring general levels of physical activity: Preliminary evidence for the physical 503 activity questionnaire for older children. Medicine and Science in Sports \& Exercise,

504 29, 1344-1349. doi:10.1097/00005768-199710000-00011

Deci, E. L., \& Ryan, R. M. (2000). The “what” and "why” of goal pursuits: Human needs and 506 the self-determination of behavior. Psychological Inquiry, 11, 227-268.

507 doi:10.1207/S15327965PLI1104_01

Deci, E. L., \& Ryan, R. M. (2012). Motivation, personality, and development within 509 embedded social contexts: An overview of self-determination theory. In R. M. Ryan (Ed.), Oxford Handbook of Human Motivation (pp. 85-107). Oxford, UK: Oxford University Press. doi: 10.1093/oxfordhb/9780195399820.001.0001

512 Edmunds, J., Ntoumanis, N., \& Duda, J. L. (2006). A test of self-determination theory in the exercise domain. Journal of Applied Social Psychology, 36, 2240-2265

514 Fenton, S. A. M., Duda, J. L., Quested, E., \& Barrett, T. G. (2014). Coach provided autonomy support predicts autonomous motivation and moderate-to-vigorous physical activity and sedentary time in youth sport participants. Psychology of Sport and Exercise. 15, 453-463.

518 Gillison, F. B., Standage, M. \& Skevington, S. M. (2011). Motivation and body-related factors as discriminators of change in adolescents' exercise behavior profiles. Journal of Adolescent Health, 48, 44-51. 
521 Goudas, M., Biddle, S., \& Fox, K. (1994). Perceived locus of causality, goal orientations, and

522

523

524 Gunnell, K. E., Bélanger, M., \& Brunet, J. (2015). A tale of two models: Changes in

525

526

527

528

529

530

531

532

533

534

535

536

537

538

539

540

541

542

543

544

perceived competence in school physical education classes. British Journal of Educational Psychology, 64, 453-463. doi:10.1111/j.2044-8279.1994.tb01116.x

psychological need satisfaction and physical activity over 3 years. Health Psychology, advance online publication. http://dx.doi.org/10.1037/hea0000259.

Hagger, M. S., \& Chatzisarantis, N. L. (2015). The trans-contextual model of autonomous motivation in education: Conceptual and empirical issues and meta-analysis. Review of Educational Research doi: 10.3102/0034654315585005

Hagger, M. S., Chatzisarantis, N. L., Barkoukis, V., Wang, C. K., \& Baranowski, J. (2005). Perceived autonomy support in physical education and leisure-time physical activity: A cross- cultural evaluation of the trans-contextual model. Journal of Educational Psychology, 97, 287-301.

Hagger, M. S., Chatzisarantis, N. L., \& Biddle, S. J. H. (2001). The influence of self-efficacy and past behaviour on the physical activity intentions of young people. Journal of Sport Sciences, 19, 711-725.

Hagger, M. S., Chatzisarantis, N. L., Culverhouse, T., \& Biddle, S. J. H. (2003). The process by which perceived autonomy support in physical education promotes leisure-time physical activity intentions and behavior. Journal of Educational Psychology, 95, 784-795.

Hagger, M. S., Chatzisarantis, N. L., Hein, V., Pihu, M., Soós, I., Karsai, I., Lintunen, T., \& Leemans, S. (2009). Teacher, peer, and parent autonomy support in physical education and leisure-time physical activity: A trans-contextual model of motivation in four cultures. Psychology and Health, 24, 689-711. 
545 Health and Social Care Information Centre. (2014). Statistics on Obesity, Physical Activity and Diet, http://www.hscic.gov.uk/catalogue/PUB13648/Obes-phys-acti-diet-eng2014-rep.pdf. (accessed 17 January 2015).

548 Hidi, S., \& Renninger, K. A. (2006). The four phase model of interest development. Educational Psychologist, 41, 111-127. doi:10.1207/s15326985ep4102_4

550 Hox, J. J. (2010). Multilevel analysis: Techniques and applications (2nd ed.). Hove, UK: $551 \quad$ Routledge.

552 Hu, L., \& Bentler, P.M. (1999). Cut-off criteria for fit indexes in covariance structure analysis: Conventional criteria versus new alternatives. Structural Equation Modeling, 6, 1 - 55. doi:10.1080/10705519909540118

Knight, G.P. \& Zerr, A. A. (2010). Introduction to the special section: Measurement equivalence in child development research. Child Development Perspectives, 4, 1-4.

557 Legault, L., Green-Demers, I., \& Pelletier, L. G. (2006). Why do high school students lack motivation in the classroom? Toward an understanding of academic amotivation and the role of social support. Journal of Educational Psychology, 98, 567-582.

Lonsdale, C., \& Hodge, K. (2011). Temporal ordering of motivational quality and athlete burnout in elite sport. Medicine \& Science in Sports \& Exercise, 43, 913-921. doi:10.1249/MSS.0b013e3181ff56c6

563 Lonsdale, C., Sabiston, C. M., Raedeke, T. D., Ha, A. S., \& Sum, R. K. (2009). Selfdetermined motivation and students' physical activity during structured physical education lessons and free choice periods. Preventive Medicine, 48, 69-73.

566 Lonsdale, C., Sabiston, C.M., Taylor, I.M., \& Ntoumanis, N. (2011). Measuring student motivation for physical education: Examining the psychometric properties of the perceived locus of causality questionnaire and the situational motivation scale. 
569

570

\section{1}

572

573

574

575

576

577

578

579

580

581

582

583

584

585

586

587

588

589

590

591

592

593

Psychology of Sport and Exercise, 12, 284-292.

doi:10.1016/j.psychsport.2010.11.003.

Marsh, H. W. (1990). The structure of academic self-concept: The Marsh/Shavelson model. Journal of Educational Psychology, 82, 623-636. doi: http://dx.doi.org/10.1037/00220663.82 .4 .623

Marsh, H. W., Byrne, B. M., \& Yeung, A. S. (1999). Causal ordering of academic selfconcept and achievement: Reanalysis of a pioneering study and revised recommendations. Educational Psychologist, 34, 155-167.

Marsh, H. W., Lüdtke, O., Muthén, B., Asparouhov, T., Morin, A.J.S., Trautwein, U., \& Nagengast, B. (2010). A new look at the big-five factor structure through exploratory structural equation modeling. Psychological Assessment, 22, 471-491. doi: $10.1037 / \mathrm{a} 0019227$

Marsh, H. W., Nagengast, B., \& Morin, A. J. S. (2013). Measurement invariance of big-five factors over the life span: ESEM tests of gender, age, plasticity, maturity, and la dolce vita effects. Developmental Psychology, 49, 1194-1218. doi: 10.1037/a0026913

McDavid, L., Cox, A. E., \& McDonough, M. H. (2014). Need fulfillment and motivation in physical education predict trajectories of change in leisure-time physical activity in early adolescence. Psychology of Sport and Exercise, 15, 471-480. http://dx.doi.org/10.1016/j.psychsport.2014.04.006.

Muthén, L. K. \& Muthén, B. O. (1998 - 2012). Mplus User’s Guide (7 $7^{\text {th }}$ Ed). Los Angeles, CA: Muthén \& Muthén.

Newman, D. A. (2014). Missing data: Five practical guidelines. Organisational Research Methods, 17, 372-411. doi:10.1177/1094428114548590

Ntoumanis, N. (2012). A self-determination theory perspective on motivation in sport and physical education: Current trends and possible future research directions. In G.C. 
594

595

596

597

598

599

600

601

602

603

604

605

606

607

608

609

610

611

612

613

614

615

616 Roberts and D. C. Treasure, Advances in Motivation in sport and exercise: Volume 3 (pp. 91-128). Champaign, IL: Human Kinetics.

Ntoumanis, N., Barkoukis, V., \& Thøgersen-Ntoumani, C. (2009). Developmental trajectories of motivation in physical education: Course, demographic differences, and antecedents. Journal of Educational Psychology, 101, 717-728. doi: 10.1037/a0014696

Ntoumanis, N., Pensgaard, A. M., Martin, C., \& Pipe, K. (2004). An ideographic analysis of amotivation in compulsory school physical education. Journal of Sport and Exercise Psychology, 26, 197-214.

Office for Standards in Education Children's Services, Skills, 2013. Beyond 2012_Outstanding Physical Education for all: Physical Education in Schools, Manchester, UK.

Owen, K. B., Smith, J., Lubans, D. R., Ng, J. Y. Y., \& Lonsdale, C. (2014). Self-determined motivation and physical activity in children and adolescents: A systematic review and meta-analysis. Preventive Medicine, 67, 270-279. doi.org/10.1016/j.ypmed.2014.07.033

Pelletier, L. G., Fortier, M. S., Vallerand, R. J., \& Brière, N. M. (2001). Associations between perceived autonomy support, forms of self-regulation, and persistence: A prospective study. Motivation and Emotion, 4, 279-306.

Prince, S. A., Adamo, K. B., Hamel, M. E., Hardt, J., Gorber, S. C. \& Tremblay, M. (2008). A comparison of direct versus self-report measures for assessing physical activity in adults: A systematic review. International Journal of Behavioral Nutrition and Physical Activity, 5:56. doi:10.1186/1479-5868-5-56 
617 Rhodes, R. E. \& Courneya,K. S. (2003). Modelling the theory of planned behaviour and past

618

619

620

621

622

623

624

625

626

627

628

629

630

631

632

633

634

635

636

637

638

639

640

behaviour. Psychology, Health, and Medicine, 8, 57-69

doi:10.1080/1354850021000059269

Ryan, R. M., \& Connell, J. P. (1989). Perceived locus of causality and internalization: Examining reasons for acting in two domains. Journal of Personality and Social Psychology, 57, 749-761.

Sherar, L. B., Cumming, S. P., Eisenmann, J. C., Baxter-Jones, A. D., \& Malina, R. M. (2010). Adolescent biological maturity and physical activity: biology meets behavior. Pediatric Exercise Science, 22, 332-349. doi:http://dx.doi.org/10.1123/pes.22.3.332

Singer, J. D., \& Willett, J. B. (2003). Applied longitudinal data analysis: Modeling change and event occurrence. Oxford, UK: Oxford University Press.

Standage, M., Duda, J.L., \& Ntoumanis, N. (2003). A model of contextual motivation in physical education: Using constructs from self-determination and achievement goal theories to predict physical activity intentions. Journal of Educational Psychology, 95, 97-110. doi:10.1037/0022-0663.95.1.97

Standage, M., Gillison, F.B., Ntoumanis, N., \& Treasure, G.C. (2012). Predicting students’ physical activity and health-related well-being: A prospective cross-domain investigation of motivation across school physical education and exercise settings. Journal of Sport \& Exercise Psychology, 34, 37-60.

Taylor, I. M., Ntoumanis, N., \& Smith, B. (2009). The social context as a determinant of teacher motivational strategies in physical education. Psychology of Sport and Exercise, 10, 235-243. doi:10.1016/j.psychsport.2008.09.002

Taylor, I. M., Spray, C. M., \& Pearson, N. (2014). The influence of the physical education environment on children's well-being and physical activity across the transition from 
641

642

643

644

645

646

647

648

649

650

651

652

653

654

655

656

657

658

659

660

661

primary to secondary school. Journal of Sport \& Exercise Psychology, 36, 574-583. http://dx.doi.org/10.1123/jsep.2014-0038

Taylor, I.M., Ntoumanis, N., Standage, M., \& Spray, C.M. (2010). Motivational predictors of physical educational students’ effort, exercise intentions, and leisure-time physical activity: A multilevel linear growth analysis. Journal of Sport \& Exercise Psychology, 32, 99-120.

Thøgersen-Ntoumani, C., \& Ntoumanis, N. (2006). The role of self-determined motivation in the understanding of exercise-related behaviours, cognitions and physical selfevaluations. Journal of Sport Sciences, 24, 393-404.

Vallerand, R. J. (2001). A hierarchical model of intrinsic and extrinsic motivation in sport and exercise. In G. C. Roberts (Ed.), Advances in motivation in sport and exercise (pp. 263-319). Champaign, IL: Human Kinetics.

van Sluijs, E. M. F., McMinn, A. M. \& Griffin, S. J. (2007). Effectiveness of interventions to promote physical activity in children and adolescents: Systematic review of controlled trials. British Medical Journal, Epub doi:10.1136/bmj.39320.843947.BE

Vandenberg, R.J., \& Lance, C.E. (2000). A review and synthesis of the measurement invariance literature: Suggestions, practices, and recommendations for organizational research. Organizational Research Methods, 3, 4-70.

Wigfield, A. \& Cambria, J. (2010). Students’ achievement values, goal orientations, and interest: Definitions, development, and relations to achievement outcomes. Developmental Review, 30, 1-35. doi:10.1016/j.dr.2009.12.001 
662 Table 1

663 Raykov’s Rho Coefficients and Latent Factor Correlations of all Study Variables

\begin{tabular}{|c|c|c|c|c|c|c|c|}
\hline & \multicolumn{3}{|c|}{ Raykov’s Rho } & \multicolumn{4}{|c|}{ Latent Factor Correlations (correlations at time 1/time 2) } \\
\hline Variable & Time 1 & Time 2 & 1. & 2. & 3. & 4. & 5. \\
\hline 1. Autonomous & .906 & .923 & & & & & \\
\hline \multicolumn{8}{|l|}{ Motivation } \\
\hline 2. Introjected & .695 & 699 & $.54 /$ & & - & & \\
\hline Regulation & & & .50 & & & & \\
\hline 3. External & .792 & .859 & $-.23 /$ & .53 & & - & \\
\hline Regulation & & & -.26 & .57 & & & \\
\hline \multirow[t]{2}{*}{ 4. Amotivation } & .801 & .878 & $-.52 /$ & $.08(p=.26)$ & .54 & & - \\
\hline & & & -.62 & $.03(p=.64)$ & .57 & & \\
\hline 5. School Physical & .729 & .743 & $.42 /$ & .29 & $.02(p=.80)$ & $-.17(p=.01)$ & \\
\hline Activity & & & .46 & .26 & $-.13(p=.05)$ & -.33 & \\
\hline 6. Leisure Time & .771 & .772 & $.29 /$ & $.09(p=.19)$ & -.19 & -.23 & .44 \\
\hline Physical Activity & & & .33 & $.21(p=.01)$ & $-.11(p=.05)$ & -.26 & .56 \\
\hline
\end{tabular}

664 Note. Unless otherwise specified, associated $p$ values with correlations are $<.001$. All scales were responded to on a 1-7 scale with the

665 exceptions of school and leisure time physical activity (1-5). All latent variables had a mean of 0 and a standard deviation of 1. 
666 Table 2

667 Fit Indices for all Models

Fit indices

\begin{tabular}{lcccc}
\hline Model & $\chi^{2}(d f)$ & CFI & RMSEA (90\% CI) & TLI \\
\hline 1. Configural baseline model & $1930.846(1182)$ & .934 & $.032(.029-.035)$ & .926 \\
2. Weak invariance (Factor loadings & $1966.949(1202)$ & .933 & $.032(.029-.035)$ & .926 \\
constrained) & & & & \\
3. Strong invariance (Factor loadings & $2010.892(1222)$ & .931 & $.032(.030-.035)$ & .925 \\
and item intercepts constrained) & & & & \\
4. Strict invariance (Factor loadings, & $2050.829(1248)$ & .930 & $.032(.030-.035)$ & .925 \\
intercepts, and residual variances & & & & \\
constrained) & & & .925 \\
5. Factor variance- covariance & $2089.766(1269)$ & .928 & $.032(.030-.035)$ & \\
invariance & & & & \\
6. Factor mean invariance & & & $.033(.030-.035)$ & .922 \\
7. Reciprocal effects model & $2132.154(1275)$ & .925 & $.030-.035)$ & .925 \\
\hline
\end{tabular}


670 Table 3

671 Standardized Path Coefficients in the Reciprocal Effects Model

Dependent Variable: $\beta$ (95\% Confidence Intervals); $p$ value

\begin{tabular}{|c|c|c|c|c|c|c|}
\hline $\begin{array}{l}\text { Independent } \\
\text { Variable }\end{array}$ & $\begin{array}{l}\text { T2 Autonomous } \\
\text { motivation }\end{array}$ & $\begin{array}{l}\text { T2 Introjected } \\
\text { Regulation }\end{array}$ & $\begin{array}{l}\text { T2 External } \\
\text { Regulation }\end{array}$ & T2 Amotivation & $\begin{array}{c}\text { T2 School } \\
\text { physical activity }\end{array}$ & $\begin{array}{l}\text { T2 Leisure-time } \\
\text { Physical Activity }\end{array}$ \\
\hline $\begin{array}{l}\text { T1 Autonomous } \\
\text { motivation }\end{array}$ & $\begin{array}{c}.52(.46-.58) \\
p<.001\end{array}$ & - & - & - & $\begin{array}{c}-.00(-.21-.20) \\
p=.99\end{array}$ & $\begin{array}{c}.13(-.04-.29) \\
p=.13\end{array}$ \\
\hline $\begin{array}{l}\text { T1 Introjected } \\
\text { regulation }\end{array}$ & - & $\begin{array}{c}.59(.54-.65) \\
p<.001\end{array}$ & - & - & $\begin{array}{c}.15(-.07-.37) ; \\
p=.18\end{array}$ & $\begin{array}{c}.13(-.06-.31) \\
p=.18\end{array}$ \\
\hline T1 Amotivation & - & - & - & $\begin{array}{c}.50(.41-.59) \\
p<.001\end{array}$ & $\begin{array}{c}-.04(-.20-.13) \\
p=.65\end{array}$ & $\begin{array}{c}.13(.01-.28) \\
p=.04\end{array}$ \\
\hline $\begin{array}{l}\text { T1 School physical } \\
\text { activity }\end{array}$ & $\begin{array}{c}.10(.00-.19) \\
p=.04\end{array}$ & $\begin{array}{c}-.04(-.15-.08) \\
\quad p=.52\end{array}$ & $\begin{array}{c}-.07(-.18-.03) \\
\quad p=.16\end{array}$ & $\begin{array}{c}-.12(-.22--.03) \\
p=.01\end{array}$ & $\begin{array}{c}.49(.42-.57) \\
p<.001\end{array}$ & - \\
\hline
\end{tabular}


PE MOTIVATION AND PHYSICAL ACTIVITY 30

673

674 
675 Figure 1

676 The reciprocal effects model

677

678

679

680

681

682

683

684

685

686

687

688

689

690

691

692

693

694

695

696

697

698

699

700
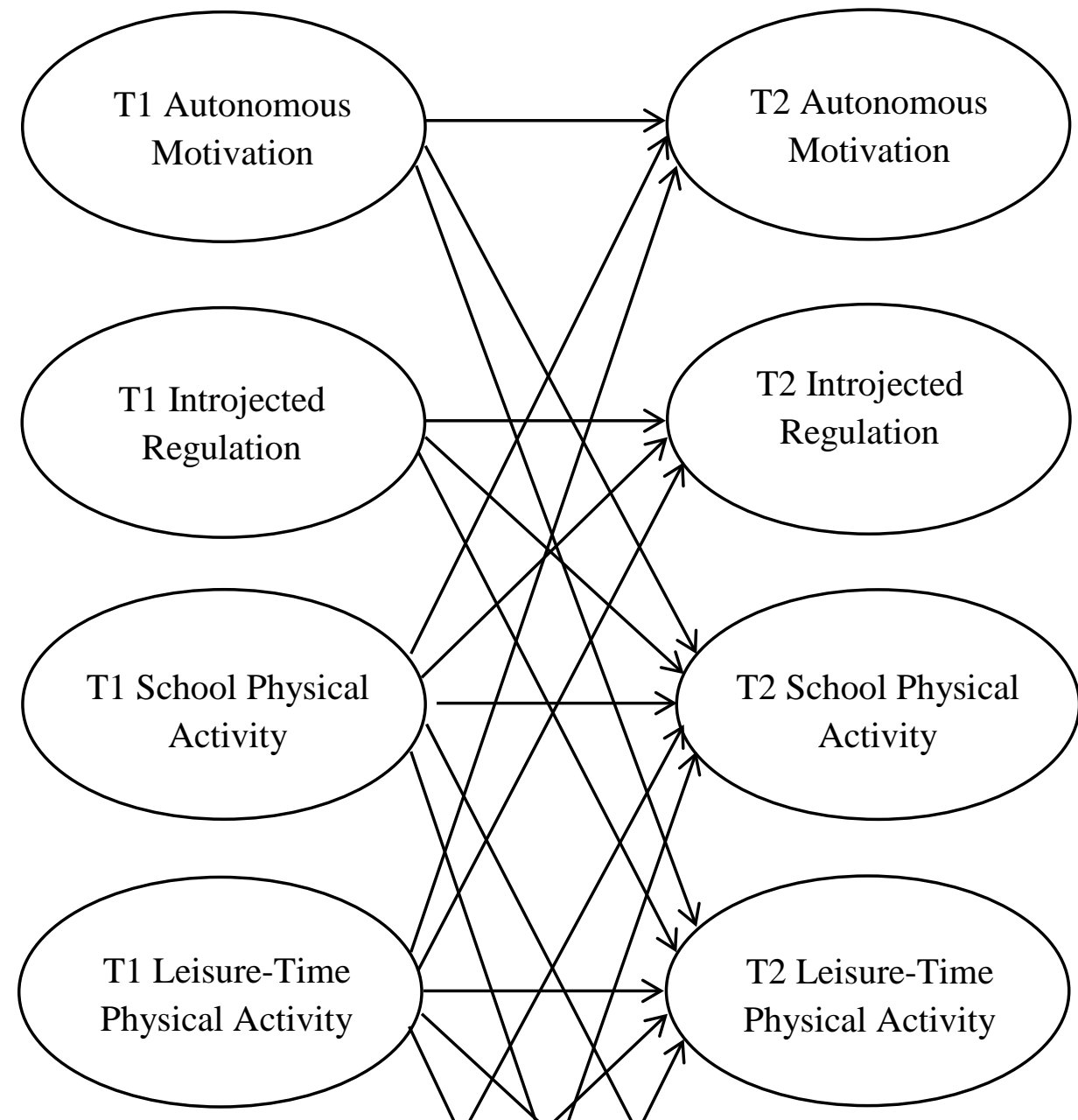

T2 Leisure-Time

Physical Activity

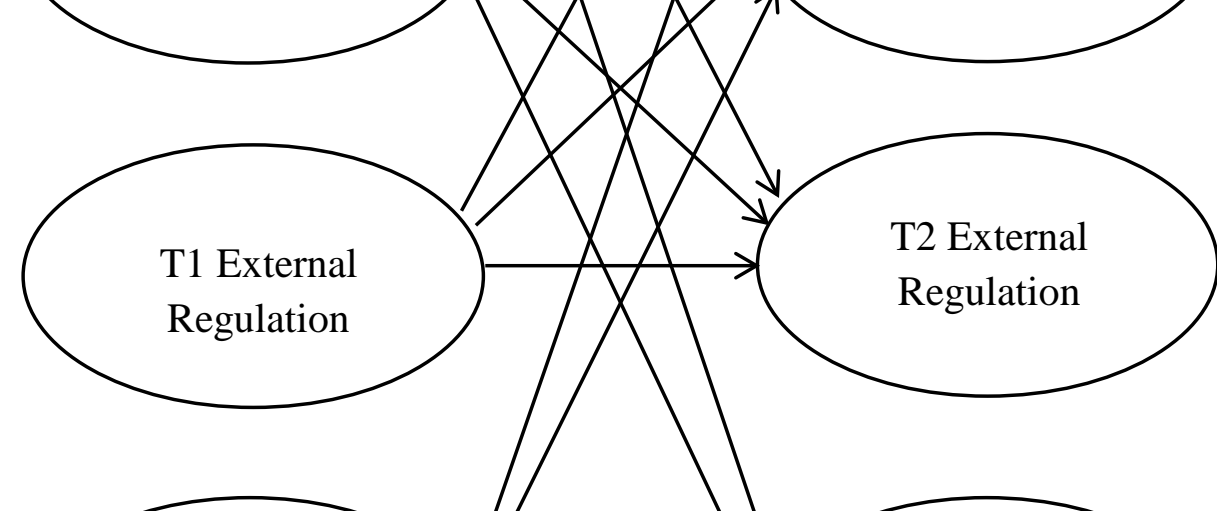

701 Note. Factor indicators, error terms, and covariance paths not shown 